\title{
VANDAL TARİHINE GENEL BİR BAKIŞ: VANDALLARIN ORTAYA ÇIKIŞI VE AFRİKA'DA KALICI BİR YURT EDINMELERINE KADAR GEÇEN SÜREÇ HAKKINDA GENEL BİR DEĞERLENDİRME
}

\author{
Mert KOZAN* \\ ORCID ID: 0000-0003-0176-0776
}

\begin{abstract}
Makale Bilgisi
Başvuru: 24 Nisan 2020

Kabul: 01 Haziran 2020
\end{abstract}

Article Info

Received: April 24, 2020

Accepted: June 01, 2020

\begin{abstract}
$\ddot{O} z$
V. yüzyıldan itibaren dăğlmaya başlayan Roma dünyasına büyük bir darbe indirmeyi başarmış bir kavim olan Vandallara bugüne değin tarihçiler tarafindan gereken önem gösterilmemiştir. Oysaki Vandallar Kartaca'yı işgal ettikleri 439'dan itibaren Batı Roma Imparatorluğu'nun gölgesinde bir kavim olmaktan çıkıp tarihte büyük öneme sahip bir krallı yaratmayı başardılar. 450-500 yılları arasında Akdeniz siyasetine hâkim oldular ve 50 yll daha hem ekonomik hem de kültürel olarak önemli bir devlet konumunda kaldılar. Ancak bu "peri masalı"nın sonu yıldırım hızılla geldi. 534 yılında Kartaca ve Vandal krallığl, Iustinianos'un Roma'yl yeniden ihya etme teşebbüsü
\end{abstract}

* Dr. Öğr. Üyesi. Ankara Üniversitesi, Dil ve Tarih Coğrafya Fakültesi, Tarih Bölümü, Ortaçağ Tarihi A.B.D.,E.Posta: mkozan@ankara.edu.tr 
neticesinde ele geçirildi ve Vandallar sonsuza kadar tarih sahnesinden çekilmek zorunda kald.

21. yüzyılda Vandallar şiddet ve kültürsüzlük için adeta bir metafor olarak kullanılmaktadır. Bu süreç kuşkusuz Fransız Devrimi'nden itibaren süre gelmektedir. Vandallar, yaşadı̆̆ımı yüzyılda özellikle Roma Cumhuriyeti üzerine yapılan güzellemeler neticesinde Roma Cumhuriyeti karşıtı grupların baş listesine eklenmiştir. Çünkü Romalıların elinde bulunan zengin eyaletlerden birini ele geçirmiş, Roma'nın Akdeniz'deki üstünlügüune son vermiştir. Ancak unutulan bir olgudur ki Roma; Vandallar Afrika'ya geçtiğinde ne cumhuriyetti ne de o eski ihtişamındaydl.

Vandal Krall Geiserich, tarih sahnesine unutulmayacak bir zamanda çıkan özel bir insandl. Geiserich toplumunun yaşadığı zor zamanlarda onlara önderlik etmiş ve yarım yüzyll gibi kisa bir süre zarfi içerisinde halkını Akdeniz'in önemli bir topluluğu haline getirmişti.

Makalemizdeki temel amaç Vandalların Afrika'ya geçişi ve burada kalıcı bir yurt edinmelerine kadar olan süreci incelemektir.

Ortaçăg.

Anahtar Kelimeler: Vandallar, Geiserich, Afrika, Erken

Abstract

A General Look At Vandal History: An Evaluation Over the Period from the Emergence of Vandals to Their Settlement in Africa

Historians have mostly overlooked the Vandals as a tribe who dealt a blow to the Roman world that had begun to dissolve after the $5^{\text {th }}$ century. Yet, since their conquest of Carthage in 439, the Vandals succeeded to become an independent and significant kingdom out of the shadow of the Roman Empire. They dominated the Mediterranean politics between 450 and 500, and they remained relevant both economically and culturally for another fifty years. However, the end of this fairytale came quickly. In year 534, Justinian I conquered both Carthage and Vandal Kingdom as part of his rejuvenation of Rome and consequently the Vandals faded into history forever.

In the twenty-first century, the Vandal is used as a metaphor of violence and philistinism. This metaphor is inherited from the French Revolution. Mostly because of the increased praise of the Roman Republic today, the Vandals are added to the list of what signifies the anti-Rome. This is basically due to the fact that the Vandals conquered one of the richest states of the Roman Republic and ended their dominance at sea. Yet it is frequently forgotten that when the Vandals settled in Africa, Rome was neither a republic nor at its former glory. 
Geiserich, the King of the Vandals, represented a special figure who came into history at an unforgettable time. He was a pioneer for his people at difficult times and made them an important part of the Mediterranean within a time period shorter than a half of century.

The main purpose of this article is to analyze the period between when the Vandals had conquered Africa and settled in this geography.

Key Words: Vandals, Geiserich, Africa, Early Middle Ages.

\section{Giriş}

V. yüzyıl, Akdeniz dünyasında tam anlamıla bir kaos dönemiydi. Batı Roma İmparatorluğunun siyasal otoritesi parçalara bölünürken, Barbar olarak adlandırılan ve Romalılar tarafından ötekileştirilen unsurlar güç kazanmaya başladılar. Bu grupların en önemlilerinden biri de Vandallar idi. Ünlü krallarından olan Geiserich Kuzey Afrika'nın zengin Roma kentlerini işgal etti ve 439 'da büyük ticaret şehri olan Kartaca'yı ele geçirdi ${ }^{1}$. Sonraki yüzyılda Vandallar ölmekte olan Roma İmparatorluğu'nun tam kalbinde hayatta kalarak başarılarını taçlandırdılar. Geiserich, 455'te Roma Şehri'ni yağmaladı ve Vandal korsanlığı, bundan sonraki on yıllar boyunca Akdeniz gemisinde sürekli bir veba olarak kaldı. Kuzey Afrika'nın kendisi içinde, Vandal yönetimi dönemi aşırılıklar dönemiydi. Vandalların Afrika'daki yönetimleri boyunca çoğu kişi Ortodoks 'Nicea' Hıristiyanları tarafından sapkın olarak görülmekteydi. Ortodoks inanç meselesi yüzünden pek çok Hıristiyanlığın farklı kolunu benimseyen kişi ve kişiler büyük zulümlere maruz kalmıştı. İşte bu yüzden özellikle kendi toplumlarının yaşadıklarını gelecek kuşaklara aktarabilmek için büyük çaba sarf edip ve bunun neticesinde yaşanılanları gelecek kuşaklara aktarabilmek maksadıyla eğitime önem verdiler. ${ }^{2}$ Büyük bina projeleri tıpkı Roma dönemindeki gibi devam etti. Eğitim tüm Roma'da çökmüştü ancak Vandallar, geç Latin Batı'sının en yenilikçi yazar ve doğa bilimcilerinin çalışmalarını destekledi; onları teşvik etti $^{3}$. Vandalların başarıları miras aldığı müreffeh İmparatorluğun hayaletiyle yakından bağlıydı. Roma döneminin en yüksek noktasında, Kuzey Afrika

1 Guido M. Berndt and Roland Steinacher, Das Reich der Vandalen und seine (Vor-) Geschichten. (Vol. 13. Verlag der Österreichischen Akademie der Wissenschaften, Wien 2008),22.

2 Peter Brown, "Christianity and Local Culture in late Roman Africa" The Journal of Roman Studies 58.1-2 (1968): 85-95; Valentino Gasparini, "Tracing Religious Change in Roman Africa" Eds. R. Raja-J. Rüpke, A Companion to the Archaeology of Religion in the Ancient World. Malden-Oxford (2015): 478-488.

3 Andy Merrills \& Richard Miles, The Vandals, (Wiley-Blackwell, Chichester 2010), 35. 
imparatorluk tacının bir mücevheri olmuştu. Afrika kentlerinin zenginliği ve verimliliği $\mathrm{V}$. yüzyılın başından itibaren ön plana çıkmıştı, Zeugitana ve Numidia'nın zengin tahıl alanları ve Byzacena'nın ve Mauretania'nın geniş zeytin bahçeleri bunların yalnızca birkaçıydı ${ }^{4}$. IV. yüzyılın isimsiz bir tüccarı Afrika'yı 'olağanüstü ve takdire şayan' olarak nitelendirmekte; V. yüzyılın bilim adamı Martianus Capella da bölgenin son derece müreffeh olduğunu aktarmaktadır ${ }^{5}$. İki buçuk asırlık dönemde, Afrika vilâyetleri büyük bir tarımsal fazlalık üretmişlerdi ve bu Roma'ya vergi olarak gönderiliyordu. $\mathrm{Bu}$ fazlalık tahıl, zeytinyağı, şarap ve balık idi ${ }^{6}$. Bölge ekonomisi bu ürün kalemlerini tüketiyor ve arta kalanları ise İmparatorluğun Akdeniz'deki diğer limanlarında büyük bir ilgi görüyordu. Buradan gelen mallar ise özellikle bölge dışındaki diğer kentlerde yüksek meblağlara satılıyordu ${ }^{7}$. Geç Roma Afrika'sındaki herkes zengin değildi, ancak bölge kesinlikle müreffehti.

$\mathrm{Bu}$ arada Afrika şehirleri kamu binaları, banyolar, tiyatrolar ve amfi tiyatrolar ile süslenmiş, zeytinyağı bölgedeki tüm lambalarda çok miktarda kullanılmış ve çiftlikler kırsalda gelişmeye devam etmişti. Kültürel açıdan ise, Roma Kuzey Afrika'sı olağan dışıydı ${ }^{8}$. İkinci yüzyılda Hıristiyanlık bölgeye gelmiş ve bundan sonra inanç belirli bir güçle gelişmişti. Azizler ve şehitler tarafından oluşturulan Afrika Kilisesi ise ancak büyük teologlar tarafindan şekillendirilmişti. İkinci yüzyılda Tertullianus ${ }^{9}$, üçüncü yüzyılda Cyprianus ${ }^{10}$ ve Arnobius ${ }^{11}$, dördüncü yüzyılda ise Lactantius vard1. Bu gelenek dördüncü yüzyılın sonlarında Kartaca'da eğitim görmüş olan Aziz Augustinus, Hippo Regius kentinin piskoposu olarak 430 'da öldüğünde sona erdi. Liderlik

4 Konrad Vössing, Das Königreich der Vandalen (Verlag Phillip von Zabern in Wissenschaftliche Buchgesellschaft, 2014), 13.

5 Detaylı bilgi için bknz: James Willis, Martianus Capella. (Walter de Gruyter 2012).

6 Fergus Millar "Local Cultures in the Roman Empire: Libyan, Punicand Latin in Roman Africa." The Journal of Roman Studies 58.1-2 (1968): 126-134.; Richard P. Duncan-Jones, "City population in roman Africa" The Journal of Roman Studies 53.1-2 (1963): 85-90.

7 Lea.M.Stirling,"The koine of the cupula in Roman North Africa and the transition from cremation to inhumation". In D.L. Stoneand L.M. Stirling (eds.), Mortuary landscapes of North Africa,(2007): 110-137.

8 Josephine Crawley Quinn, 2003. Roman Africa? Digressus Supplement, 1, 'Romanization'?,: The Institute of Classical Studies, (2003): 7-34.

9 Quintus Septimius Florens Tertullianus, The Five Books of Quintus Sept. Flor. Tertullianus Against Marcion., Vol. 7., (Edinburgh Clark, 1868), 5:10.

10 Peter Heylyn, Cyprianus Anglicus: Or, The History of the Life and Death, of the Most Reverendand Renowned Prelate William by Divine Providence, Lord Archbishop of Canterbury... Containing Also The Ecclesiastical History of the Three Kingdoms of England, (Scotland, and Ireland from His First Rising Till His Death. A.Seile, 1719), 62-64

11 Simon Price, "Latin Christian Apologetics: MinuciusFelix, Tertullian, and Cyprian."in (Apologetics in the Roman Empire: Pagans, Jews, andChristians Oxford 1999), 105-130. 
görevini üstlenmiş olduğu kilise ve topluluk Vandallar tarafından kuşatıldı, ancak yok edilemedi ${ }^{12}$; bölgede Hristiyanlığın etkisini kırmak için İslam'ın Kuzey Afrika'ya yayılmasına kadar beklemek gerekecekti.

Biz her ne kadar Vandal toplumunu Afrika'da kurduğu krallık dolayısıyla detaylı olarak biliyor olsak da bu toplumun tarihi çok daha eskilere dayanmaktadır.

\section{Vandallar Tuna'da İ.S. 171:}

İ.S. 171'de Asding adında bir barbar grubu, Roma'nın Dacia eyaletine girdi. Bu topluluğa Raus ve Raptus adında iki kral önderlik ediyordu ${ }^{13}$. Sanılanın aksine bu topluluk Roma'nın Dacia Eyaletinde yağma için değil bilakis ittifak arayışı için bulunuyordu. Dönem, Roma İmparatorluğu'nu ve İmparator Marcus Aurelius için zor bir dönemdi; İmparator beş yıl boyunca Orta Tuna sınırında Marcomanni ve Quadi kavimlerine karşı sefer yürütüyordu, ancak 170 'den bu savaşlar, Tuna sınırını geçerek Tuna'nın aşağı vilayetlerine yayılma eğilimi göstermekteydi. Tuna'nın ötesindeki tek Roma eyaleti olan Dacia valisi Cornelius Clemens' in yüzleşmesi gereken belli başlı "barbar" sorunları vardı. Bunlar ise Lacringi, Costobocive Asding kavimleriydi. Elbette Romalıların klasik Roma politikası gereği bu kavimleri birbirine düşürmesi gerekiyordu. Bunun için Asdingleri, Costoboci kavmine saldırması için teşvik etti. Ancak Asdingler bu konuda çekimser ve tarafsız kaldılar. Belki de hayati öneme sahip bir karar vermişlerdi. Çünkü bu olayın hemen ardından Lacringi kavmi Asdinglere saldırmakla birlikte başarısız olmuşlard1. Böylelikle Asdingler Roma için değerli bir müttefik olabileceklerini Clemens'e kanıtlamış oldular ${ }^{14}$.

Cassisus Dio tarafindan aktarılan bu bilgi Vandal tarihi ile ilgili elimizdeki en erken kayıtlardan biri olma özelliği göstermektedir ki, bu aynı zamanda Vandal tarihinin en eski parçalarının tipik bir örneğidir ${ }^{15}$. Genel olarak Asdinglerin Vandallar olduğu varsayımı kabul edilmektedir "Asdingadı daha sonra Vandalların kraliyet ailesi tarafından, V. yüzyılın başları ile Afrika krallığının çöküşü arasında 530'larda kabul edildi”; ancak bundan daha fazlasını söyleyemeyiz. Bu grubun Tuna Bölgesi'ndeki diğer

12 Peter Garnsey, "Taxatio and pollicitatio in Roman Africa." The Journal of Roman Studies 61 (1971): 116-129.

13 Klaus Tausend, "Bemerkungen zum Wandalen einfall des Jahres 271." Historia: Zeitschrift für Alte Geschichte (1999): 119-127.

14 Andrew Merrills, Vandals, Romans and Berbers: New Perspectives on Late Antique North Africa. (Routledge, 2017), 16.

15 Pohl, Walter. "The Vandals: fragments of a narrative." Vandals, Romans and Berbers. (Routledge, 2017), 47-64. 
"Vandal"lar ile nasıl bir bağlantısının olduğunu bilmiyoruz. Bu barbar grupların neden iki kral tarafından idare edildiğini ve aralarındaki ilişkinin ne olduğu konusunda da fikir yürütemiyoruz ${ }^{16}$. Aynı ş̧ekilde, Roma Dacia'sındaki, Asding'in eylemleriyle ilgili çok az bilgiye sahibiz ${ }^{17} . \mathrm{Bu}$ bölgede Vandallar erken tarihi için metinsel kaynakların hepsi sorunludur. Jordanes özellikle Vandalların IV. yüzyıldaki yeri ile ilgili detaylı bilgi verir; elbette bunu Gotların kazandığı büyük zaferleri betimlemek için yapmaktadır; ancak bizim için önemli olan husus Vandalların IV. yüzyıldaki bulundukları yer ile ilgili detaylı bilgi vermesinden ileri gelmektedir. Getica'da Jordanes, Got Kralı Geberich'in büyük bir zafer kazandığından bahseder; bu zafer Tuna Nehri'nin doğusunda ikamet eden Vandalların Roma sınırını geçmek zorunda kaldığını kayda geçmiştir ${ }^{18}$. Ancak Jordanes'in verdiği bu bilgiler dışında herhangi bir kaynakta böyle bir Vandal Krallığının varlığından ve bu yenilginin ardından çok sayıda insanın Roma sınırına doğru kaçtığından hiçbir şekilde bahsedilmez. Ayrıca Orta Tuna'nın arkeolojik kanıtları, bu dönemdeki Vandalların tutarlı bir siyasi topluluğa dönüştügü fikrini de tam olarak karş1lamamaktadır. Gotlar ve Vandallar birbirlerinin ezeli düşmanı olarak bilinmektedirler ki bu önerme son derece doğru olmakla birlikte ancak V. ve VI. yüzyıllar için geçerli bir önermedir. Çünkü III. ve IV yüzyılda bu olgudan bahsedebilmek son derece güçtür. Bu da bize Jordanes'in kayıtlarını VI. yüzyıl perspektifinden o dönemin koşulları içerisinde ortaya konulmuş oldukça tutarlı bir yaklaşım olarak görmek imkânı vermektedir ${ }^{19}$. Elbette bu yüzyılda Gotların ezeli düşmanı Vandallar idi ki, Got Tarihi yazan bir tarihçinin IV. yüzyılda kazanılmış küçük bir zaferi bile abartması son derece tutarlı bir yaklaşım idi. Arkeolojik kayıtlarla birlikte değerlendirildiğinde II. yüzyılın ortaları ve IV. yüzyılın sonlarında bu bölgeye bakacak olursak bu bölgede yaklaşık olarak 50 tane farklı Barbar organizasyonun olduğu göze çarpacaktır. Bu büyük resmi değerlendirecek olursak arkeolojik kanıtlarla birlikte bu büyük resim içerisinde Vandalların sadece küçük bir figüran olarak

${ }^{16}$ Konu ile ilgili detaylı bilgi için: Istvánovits, Eszter, and Valéria Kulcsár "Sarmatiansor Germans: Influence or Ethnic Presence Oldproblem-Newhypotheses" Inter Ambo Maria Northern Barbarians from Scandinavia towards the Black Sea (2013): 146.

17 Opreanu, "Roman Dacia and its Barbarian Neighbours, Economic and Diplomatic Relations", in Waateringe, W.G.V., Beek, B.L.V., Willems, W.J.H., Wynia, S.L. (ed.) Roman Frontier Studies. Oxford, (1997): 247-252.

18 Iordanes, and Alfred Holder. Iordanis De Origine Actibusque Getarum. Mohr, 1882; XXII, 115.; Norbert Wagner, Getica: Untersuchungen zum Leben des Jordanes und zur frühen Geschichte der Goten. Vol. 22. (Walter de Gruyter GmbH\&Co KG, 2016), 45; Herwig Wolfram, "Norbert Wagner, Getica. Untersuchungen zum Leben des Jordanes und zur frühen Geschichte der Goten." Institut für Österreichische Geschichtsforschung, Mitteilungen 76 (Wien, 1968): 256.

19 Iordanes, and Alfred Holder, Getarum. Mohr, 1882; XXII, 113,114,115. 
rol oynadığını düşünmek mantıklı bir yaklaşım olacaktır. Bu farklı barbar organizasyonlarından bazıları kuşkusuz oldukça önemliydi ki, Marcomanni ve Quadi sınırdaki komutanlar için sürekli bir endişe kaynağı olup, Gotların hareketleri ise bu dönem boyunca görülmemiş bir öneme yükselecekti. Vandallar yaşadıkları sınır boyunca önemli bir figür olmaktan çok uzaktılar ve Roma'nın barbar komşularının dördüncü yüzyıldaki 'Verona Listesinde' dahi görünmüyorlardı. Açıkçası Romalıların ana kaygıları arasında değillerdi. Modern çalışmalar ya bu göreceli belirsizliği göz ardı etmekte ya da Vandalların Yunan ve Roma kaynaklarında yer almamasını, grubun merkezinin, imparatorluğun sınırından çok uzakta olduğunu vurgulayarak açıklamaktadırlar ${ }^{20}$. Vandallarla ilgili direk bir kanıt olarak 270 yılına gitmemiz gerekecektir ${ }^{21}$. Bu tarihte modern Budapeşte'nin yakınlarında olan Aquincum'a Tuna nehrini aşıp yaklaşan bir Vandal savaşçı grubu gözlemlemekteyiz ki, bu grup, kuzey Pannonia'nın kırsal bölgesi civarında dolaşmakla birlikte kasabalara ciddi bir tehdit oluşturmamıştır. Çünkü İmparator Aurelianus'un hayvanların ve ekinlerin saldırganlardan korunmas1 amacıyla şehirlere nakledilmesine karar vermesi neticesinde zayıflamış ve belki de kış mevsiminde kendileri için yeterli yiyecekleri alamayan Vandallar İmparator tarafından kesin bir şekilde yenilgiye uğratılmıştı. Dexippus Fragmentlerin de bu yenilgiyi izleyen antlaşmanın özetini sunmakta, Vandalların sınırdan geri çekilmeye zorlandıklarını, ganimetlerini Roma ordusuna teslim etmeye ve 2.000 süvariden oluşan asker vermek zorunda kaldıklarını anlatmaktadır ${ }^{22}$. Zosimos'un verdiği bilgiye göre de Vandallar İmparator Probus (276-282) döneminde ortaya çıkmaktadır. İmparator Ren Nehri bölgesinde dolaşan bir takım Germen ve Frank kabilelerine karşı Vandallar ve Burgondiyalılardan oluşan karışık bir ordu kurmuş ve bölgeye sefer düzenlemiştir. Bu seferle ilgili çok fazla bilgi bulunmamakla birlikte seferin İmparator tarafindan başarı ile tamamlandığı anlatılmaktadır ${ }^{23}$.

20 Arnold H.M. Jones, "The date and value of the Verona List" The Journal of Roman Studies, 44.1-2 (1954): 21-29.

21 Ian Hughes, Gaiseric: The Vandal Who Destroyed Rome. (Pen and Sword, Barnsley, 2017), 34; Andrew Merrills and Richard Miles. TheVandals, 30.

22 Merrills, Andrew, ve Richard Miles. The Vandals, s. 30; Dexippus, Fragments, Karl Müller (ed.), FHG III (Paris, 1849), Fr. VII.; Mallan, Christopher, ve Caillan Davenport. "Dexippus and the Gothic Invasions: Interpreting the New Vienna Fragment (Codex Vindobonensis Hist. gr. 73, ff. 192 v-193 r)." The Journal of Roman Studies 105 (2015): 203-226.

23 Zosimus, Historicus Zosimus. Zosimi comitis exadvocati fisci Historia Nova, (Georg Olms Verlag 1963), 2,16,3; Zosimus, Historicus, and Ronald T. Ridley. New history. Australian Assoc. For Byzantine Studies, 1982; 1963; Schmidt, Anna Magdalena. "Die Rhein überquerung der Vandalen, Alanen und Sueben-Ursachen, Datierungund Übergang." historia. scribere 5 (2013): 319-335. 


\section{Vandal Tarihi için Bir Dönüm Noktası (İ.S. 406):}

Pek çok tarihçiye göre Batı Roma İmparatorluğu'nun çöküşünün nedeni 406 yılında yaşanan hadiselerdir. Gerçekleşen tek bir olay başlı başına bir neden olmasa da yıkılışın sebeplerinden bir tanesidir. Dolayısıyla 406 yılının Roma tarihi açısından ikonik bir öneme sahip olduğunu söylemek çok da yanlış olmaz. 406 yılında Vandallar Ren Nehri'ni geçerek İmparatorluğun içlerine kadar girme firsatı bulmuşlardır. Tarihi kaynaklar Ren'in nereden geçildiği konusunda sessiz kalmaktadırlar. Ancak Edward Gibbon'a göre Ren Nehri'nin donduğu bir esnada geçilmiştir ${ }^{24} \mathrm{ki}$, Ren Nehri'nin sert geçen kışlarda ve aşırı soğuk havalarda zaman zaman donduğu bilinen bir gerçektir. Gibbon bu iddiasını Aquitaine'li Prosper'e dayandırmakla birlikte ${ }^{25}$, Prosper'in bu konudaki ifadeleri net değildir. Bazı modern tarihçiler Antik dönem kaynaklarının sessiz kalmasından dolayı geçişin Worms ve Mainz kentlerinin arasında kalan bir veya birkaç bölgeden gerçekleştiğine inanmaktadırlar. Çünkü her iki kentte geçişin hemen sonrasında saldırıya uğramıştır. Bu konuda kesin olarak söyleyebileceğimiz şey Vandallar, Alanlar ve Süevlerin bilemediğimiz bir nedenden dolayı 406 veya 407 yılında Ren nehrini yerini de tam olarak bilemediğimiz bir noktadan geçmiş olduklarıdır. $\mathrm{Bu}$ yıllarda geçen olaylar ile ilgili Gallia'da yazılmış birçok kayıt olmakla birlikte bu kayıtların bir kısmı Ren Nehri'ni geçen barbar kavimleri hakkında neredeyse hiçbir bilgi vermemekte ve daha çok barbar kavimlerin Ren'i geçtikten sonra yaptığı faaliyetlere yoğunlaşmaktadırlar. Bunlardan en meşhuru olan Aziz Jerome'un kayıtları olayı şu şekilde aktarmaktadır:

"Bir zamanlar soylu olan Moguntiacum şehri ele geçirilerek yok edildi ve kilisesinde binlerce insan katledildi. Uzun bir kuşatmanın ardindan Vangium halkı bitap düşü̈. Güçlü Rheims şehri, Ambiani, Altrebatoe, dünyanın eteğinde yaşayan Belçikalılar, Tournay, Spiers ve Strasburg Almanya'ya düşü: Bu büyük ylkım sahnesine karşl Aquitaine, Lyons ve Narbonne illeriyle birkaç şehir istisna olarak kaldl. Kıtlık her yere hakim oldu......" 26

Jerome'un kayıtlarına göre ilk yıkılan şehir günümüz Mainz'ı idi. Kent yakılıp yıkılmış ve sakinlerinin çoğu katledilmişti. İmparatorluğun pek çok birliğinin İtalya'ya götürüldüğü bilgisine rağmen, Gallia'daki Roma kuvvetlerinin gücü Vandallar ve müttefikleri tarafindan tam olarak bilinmediğinden Vandallar İmparatorluk tarafından saldırıya uğrayacaklarını

24 Edward Gibbon, History of the Decline and Fall of the Roman Empire, (London, 17761789), ed. David Wormesley, 3 vols. (London, 1994), 10.

25 Gibbon, Roman Empire, 10.

26 Jerome, Epistulae, I. Hilberg (ed.), CSEL 54 (Vienna, 1910), 123.16. 
beklemekteydiler. $\mathrm{Bu}$ nedenle ihtiyatı elden birakmayan Vandallar kendilerinden daha kuvvetli bir Roma gücünün ani bir saldırısı karşısında hemen geri çekilebilmek amacıyla sınır bölgelerine yakın kalmayı tercih etmişlerdi. Ayrıca Vandalların hesaba kattıkları bir başka tehdit unsuru ise Franklar idi ki, bu nedenle Vandallar, kendileri ile Franklar arasında uygun bir mesafe bırakmayı ihmal etmemişlerdi. Dolayısıyla Vandallar Mainz'1 yağmaladıktan sonra güneye hareket ettiler ve Vangium'ya (Augusta Vangionum: Worms) saldırdılar. Mainz'in uğradığı saldırıdan ders alan Worms halkı şehirlerini savunmakla birlikte maruz kaldıkları uzayan kuşatma sonucunda pes ettiler ve Vandallar'ın şehre girişini engelleyemediler. Böylece Mainz'ın kaderini Worms kenti de paylaşt1 ${ }^{27}$.

$\mathrm{Bu}$ arada Vandallar'ın Roma ordusundan beklemekte oldukları saldırı gerçekleşmediği gibi Gallia'da görevli Magister Militumper Gallias olan Gaudentius $^{28}$ da bu olaylara herhangi bir tepki vermedi. Vandallar bundan sonra Reims kentine ilerlediler ve o da öncekilerle aynı kaderi paylaşmak zorunda kaldı.

\section{Vandallar Güney Fransa'da}

Bu kaos ortamında, yani 409 yılı ortalarında, Vandallar, Alanlar ve Süevler, Aquitaine'ye ve Pirene'ye doğru yürüdüler. Güneye doğru yapılan bu ilerleyiş neredeyse hiçbir mukavemete uğramadan devam etti. Gerontius, barbarları Konstantin'e saldırmaya teşvik edebilirdi ancak Gerontius bunu tercih etmedi diğer yandan Konstantin, kuzeydeki savaş gruplarını alıp bunlardan faydalanmaya değecek bir kaynak olarak gördüğü anlaşılıyor. Bu grupların bir kısmını kendi ordusunda kullandı. Fakat bu sanılanın aksine çok yüksek sayılarda değildi. Kuzey Gallia'daki emperyal varlık çökerken, Armorica ve güney İngiltere sakinleri imparatorluğa son kez yardıma koşması için yalvardılar; çabaları sonuçsuz kaldı. Barbarlar güneydeki korumasız topraklara doğru ilerledi. Güneydeki Gallia'ya yapılan barbar saldırıları bu berbat manzarada bile uzun zamandır hatırlanıyordu. Şair Orientus, durumu şu şekilde özetlemiştir:

"Bütün Gallia, tek bir cenaze ateşinin dumanıyla doluydu""29.

Dönemin diğer şairleri için, Gerontius ve Konstantin arasındaki kaos ve daha sonra 410'lardaki Vizigotların işgali, toplamda müthiş bir tablodur.

27 Justine Davis Randers-Pehrson, Barbarians and Romans: the Birth Struggle of Europe, AD 400-700. (U.K, Taylor \& Francis, 1983), 109.

28 İleride Roma tarihinin belki de en önemli isimlerinden birisi olan Flavius Aetius'un babas1.

29 Karl Schenkl, Poetae Christiani Minores I ...Probaecento, Tityrussiue Versus ad Gratiam Domini, De uerbiincarnatione, De ecclesia, (Viena CSEL 16, 1, 1888), 533-554. 
Fakat Vandalların etkisi hepsinden fazla olmuştu. Hydatius bu konuda önemli kaynaklarımızındın birisidir. Hydatius Hispania'daki yerleşimlerle ilgili şunları dile getirmiştir:

"Daha sonra yerleşim yerlerinin çok sayıda bölgeyi kendi aralarında paylaştılar: Vandallar, Süevler, okyanusun batı ucunda bulunan Galiçya'nın bir parçasını aldılar. Alanlar Lusitania ve Carthaginiensis ve Siling Vandalları Baetica illerini ele geçirdiler. Felaketlerden kurtulan şehirlerde ve kalelerde bulunan İspanyollar, iller boyunca sürüp giden barbarlar altında kendilerine teslim oldular." ${ }^{30}$

Hispania bölgesi Roma tarafından 5 bölgeye ayrılmıştı. Bu beş ana eyaletlerinden dört tanesi farklı barbar grupları tarafindan kontrol altına alınmıştı. Beşincisi Tarraconensis ki bu eyalet Roma'nın Hispania'daki siyasi merkezi konumundaydı; gaspçı Maximus tarafından kontrol ediliyordu. $\mathrm{Bu}$ taksimatta dikkat çekici başka bir özellik ise Alanların en geniş sahayı kontrol etmesi; buna mukabil Hasding Vandallarının ve Süevlerin kontrol ettikleri alanların kisitlı olmasiydı.

Gaspçı Maximus'un 411 yılında ölmesinden sonra buradaki ve Gallia'daki Roma otoritesi git gide zayıflamaya başladı. Gallia eyaleti başta olmak üzere pek çok eyalette barbar akınları hızlandı. Özellikle Franklar 411 yılından sonra Gallia'nın içlerine doğru taarruzlara başladı ${ }^{31}$. Hispania'da da durum farksızdı. Yine 411 yılından itibaren Vandallar pek çok yağma seferi yapmaya başlamışlardı ancak bundan yaklaşık olarak dört yıl sonra konjonktür bir kez daha değişecekti. 410 yılında Roma'nın yağmalanmasından sonra Alaricus önderliğinde Gotlar kendilerine yurt aramış ve elde etmişlerdi ${ }^{32}$. Roma ile feodus anlaşması yapan Gotlar Aquitania bölgesine yerleştirilmiş ancak bunu Alaricus görememiştir. Alaricus 40 yaşında öldügüñnde oğullarının küçük yaşta olması ve Got asilzadelerinin onları krallık için yeterli görmemesinden dolayı Athaulf Gotların kralı olarak seçilmiştir. Athaulf'un Gotları 411 yılına kadar İtalya'da mevcut konumunu korumuştur ${ }^{33}$.

30 Hydatius, The Chronicle of Hydatius and the Consularia Constantinopolitana: two contemporary accounts of the final years of the Roman Empire, (Clarendon Press, Oxdord, 1993), 175.

31 Ian Wood, 'Kings, Kingdoms ve Consent', P. H. Sawyer ve Ian Wood (ed.), Early Medieval Kingship (Leeds, 1977), 6-29.

32 Herwig Wolfram, History of the Goths, (Univ of California Press, 1990), 158.

33 Herwig Wolfram, The Roman Empire and its Germanic Peoples, (Univ of California Press, 1997), 145. 
$\mathrm{Bu}$ esnada Gallia'da yüksek rütbeli üyelerden biri olan Jovinus, İmparatorun statüsünü gasp etmişti. Buna karşın o, Burgundiyalılar, Alanlar ve diğer Germen kavimlerin oluşturduğu koalisyonun ilerleyişi sebebiyle geri çekilmiştir. Ren Nehrinin sol tarafında Burgundiyalılar daha sonra kendi Krallıklarını kurmuşlardır. Athaulf ve Gotlarının Italia'da bulunmasından rahatsız olan Jovinus'a karşılık Athaulf koalisyona katılmak istemiş, İmparator bu esnada iki taraf arasında aracilık ederek 412 y1lı boyunca da Gotların Italia'da kalmasını sağlamıştır ${ }^{34}$.

Athaulf, Alaricus'un Afrika'ya geçiş hayalini gerçekleştirmek istiyordu ancak henüz Gotların böyle bir sefer için hazırlıklı olmadığının, bu sebeple bir süre daha Roma'ya bağlı kalması gerektiğinin farkındaydı. Bu farkındalık sebebiyle İmparator Honorius'u kendi taleplerine de uygun olacak şekilde bir anlaşma yapmaya ikna etmesi gerekiyordu. Athaulf, anlaşma için Gotlar Roma'ya sahipken yakalanan ve o sirada halen tutsak olan İmparatorun en sevdiği kız kardeşi Galla Placidia'yı öne sürmüştür ${ }^{35}$. Onun isteklerine uygun bir anlaşma yapıldığı takdirde Placidia İmparatora teslim edilecektir. Honorius, bu talep karşısında Athaulf'un Gallia'ya giderek orada kendini İmparator ilan etmiş olan Jovinus'la savaşmasını istemiştir. Vizigotlar, Gallia'ya girdiğinde Athaulf, savaş olmadan problemi çözmek istiyordu ${ }^{36}$. Bu nedenle Attalus aracılığ 1 ile Jovinus'la anlaşmak istedi. Ancak Jovinus'la anlaşamayan Athaulf Honorius ile anlaşmış ve İmparatorluğa bağlı olarak Gallia'ya 412 y1lında hareket etmiştir. Romalılar, Vizigot Foederati birliklerini 412 yılında Gallia Narbonensis'e ve batı Aquitania'ya yerleştirmişlerdir Alaricus'un yerine geçen Athaulf topraklarını genişletmek istemekteydi ${ }^{37}$. Hispania üzerine bir sefer düzenledi seferin muhatabı doğrudan Vandallar idi. Jordanes Getica isimli eserinde bu olayı detaylı bir şekilde anlatmıştır. Jordanes'e göre Vandalların devamlı suretle olan akınlarından bıkmış yöre halkının talebi üzerine barış getirmek maksatlı bir harekât düzenliğini dile getirmektedir ${ }^{38}$. Bu esasında Jordanes'in Gotların yaptığı eylemlere meşruiyet kazandırmak için giriştiği çabadan başka bir şey değildi. Athaulf önderliğinde Gotlar 415 yllında

34 Guido M. Berndt, 'Gallia-Hispania-Africa: Zu den Migrationen der Vandalen auf ihrem Wegnach Nordafrika', in Guido M. Berndt and Roland Steinacher (eds.), Das Reich der Vandalen und seine (Vor-)(Geschichten, Österreichische Akademie der Wissenschaften Forschungen zur Geschichte des Mittelalters, 13,2008, Vienna), 131-47.

35 Vict. Vit., HP III.17-20.

36 Danuta Shanzer, 'Intentions and Audiences: History Hagiography, Martyrdom and Confession in Victor of Vita's Historia Persecutionis', A. H. Merrills (ed.), Vandals, Romans and Berbers: New Perspectives on Late Antique North Africa (London, 2004), 271-90.

37 Wolfram, The Goths, 162.

38 Charles C. Mierow, The Gothic History of Jordanes in English Version: With an Introduction and Commentary; (Princeton University Press, 1915); XXXI, 159. 
Katalonya bölgesine büyük bir askeri sefer başlattı. Ancak 415 yılında burada bir suikaste kurban gitti ve yerine Vallia geçti. Roma ile yaptıkları müttefiklik anlaşması gereğince Roma'nın emri ile Siling Vandallarına ve Alanlar'a saldıran Vizigotlar büyük başarılar elde ettiler. Bu savaşlar neticesinde Alan ve Siling Vandallarının kralları hayatlarını kaybettiler ve bunların bağımsızlıkları ellerinden alındı. Bu iki topluluktan geriye kalanlar Hasding Vandallarına sığındılar. Ancak nedenini tam olarak bilmediğimiz bir durumdan ötürü Vizigotlar Hasdinglerin üzerine yürüyecekken Roma tarafindan tekrar Aquitainia'daki topraklarına geri dönmek zorunda bırakıldılar ${ }^{39} .418$ yılında Vizigotlar Hispania'yı tamamen terk ettiler. Buradaki boşluktan elbette Hasding Vandalları yararlandı. İber yarımadasının güney kısmının fethi 422 yılında tamamlandı. Yine aynı yıl Baetica bu grubun eline geçti. Sevilla'dan Cartagena'ya kadar olan bütün deniz kıyısı yine ele geçirildi. Denizcilikteki başarılı adımlarını daha bu yıllarda atmaya başlayan toplum takip eden yıllarda Balear Adalarına yağma seferleri düzenleyecek kadar denizcilikte ileri gittiler ${ }^{40}$.

\section{Vandal Tarihinde bir dönüm noktası Geiserich:}

Dünya tarihini değiştirebilmiş bu kapasiteye ulaşabilmiş lider sayısı son derece azdır. İşte bu azlık içerisinde Geiserich ${ }^{41}$ bir toplumun kaderini değiştirme kapasitesi gösterebilmiş bir lider konumundadır ${ }^{42}$. Sürekli farklı kavimlerin boyunduruğu altında yaşamaya mecbur bir kavim olan Vandalların tarihini kökten değiştirmiş $V$. yüzyılın ikinci yarısından itibaren ise bu topluluğu Akdeniz coğrafyasının en önemli güç unsurlarından birisi haline getirmiştir. Geiserich ile ilgili bilgiler genellikle onun vahşiliğine ve gaddarlığına yapılan atıflarla başlar. Bunun temel nedeni Geiserich'in Nicea Amentüsü taraftarlarına karşı yürüttüğü sert politikalardan ileri gelmektedir. Geiserich gerçekten Nicea Amentüsü taraftarlarına ve bu itikata dâhil kilise mensuplarına gerçekten büyük işkenceler çektirmiştir. Batı Roma İmparatorluğu'nun artık çöküşe geçtiği evrede "Sonsuz Şehir"i yağmalamış ve adeta taş üstünde taş bırakmamıştır. Hatta literatüre bu yapılanlar daha sonrası Fransız Devrimi esnasında Vandalizm ${ }^{43}$ olarak tarihe geçmiştir. Ancak Geiserich başlı başına bunlardan farklı düşünülmesi gereken yetenekli bir Kral portresi çizmektedir.

\footnotetext{
39 Hyd.,Chron. 299.24

40 Andy Merrills\& Richard Miles, TheVandals, 66.

41 Detaylı bilgi için bknz: Hughes, Ian. Gaiseric: The Vandal who Destroyed Rome. Pen and Sword, 2017.

42 Detaylı bilgi için bknz: Peter Heather, "Gaiseric, king of the Vandals and Alans, 428-477 CE." Oxford Research Encyclopedia of Classics. 2015.

$43 \mathrm{https} / / /$ sozluk.gov.tr/?kelime=vandalizm; erişim tarihi 14.04.2020.
} 
Geiserich ile ilgili bilgilerimiz ilk yılları hariç son derece geniştir. Geiserich'in babası 406 yılında Ren sınırını geçmeye çalışan Godegisel'dir. $\mathrm{Bu}$ geçiş esnasında yapılan savaşlar neticesinde hayatını kaybetmiş̦tir ve yerine Geiserich'in üvey kardeşi olan Gunderic geçmiştir. Geiserich'in annesinin ismi bilinmemektedir ${ }^{44}$. Annesinin kökeni hakkında ise birçok tartışma vardır ancak genel görüş Geiserich'in annesinin Roma kökenli bir köle olabileceği yönündedir ${ }^{45}$. Bunu Geiserich'in ilk yıllarında Katolik itikata mensup olmasından dolayı düşünen müelliflerin sayısı bir hayli fazladır. Herwig Wolfram'da bu görüşü desteklemektedir. Geiserich'in doğum tarihinin $390^{\prime}{ }^{\prime} 1$ yıllar olduğu tahmin edilmektedir ${ }^{46}$. Çünkü taht kendisine geçtiğinde 40'l yaşlarda olduğu kaynaklar tarafından belirtilmektedir. Her ne kadar Geiserich'in doğum tarihini tam olarak tespit edemesek de Geiserich'in doğduğunda İmparatorluk sınırlarının dışında olduğunu biliyoruz. Annesi ise muhtemelen bu tarihten önce yapılan yağmalar neticesinde ele geçirilen Romalılardan birisidir. Geiserich'in üvey kardeşi 379 yılında doğduğundan dolayı Godegisel'in hayatını kaybettiği tarih olan 406 yılında tahta Gunderic geçmiştir $^{47}$. Gunderic yaklaşık olarak 428 yılına kadar hayatta kalmıştır. Gunderic'in ölümüyle ilgili Hydatius şunları kaydetmiş̧tir:

"428 Vandalların kralı Gunderic, Hispalis'i ele geçirdi, ancak kısa bir süre sonra, o şehrin kilisesine el koymaya çalıştı̆̆ında, Tanrı'nın isteğiyle bir iblis tarafindan ele geçirildi ve öldü." ${ }^{48}$

Gunderic'in ölümü Hydatius tarafından bu şekilde betimlenmiştir.

\section{Vandallar'ın Afrika'ya Geçişi}

428 Vandal tarihi açısından önemli bir dönüm noktasını ifade etmektedir. Bu yıl hem Krallık el değiştirmiş hem de Afrika'ya geçilmiştir. Ancak bu yılın hemen öncesinde Vandallar Hispania'daki konumlarını güçlendirmişlerdir. Pek çok şehre yağma akınları düzenlenmiş ve deniz üzerinden de bir takım yağma faaliyetleri gerçekleştirilmiştir. 420’li yıllardan itibaren Batı Akdeniz'in siyasi haritasında bir takım değişiklikler vuku bulmaya başlamıştır. Bunların başında Süevler ve Vizigotlar konumlarını güçlendirmeye başlamışlardı. Orta Akdeniz'de ise tam bir karışıklık hâkimdi.

44 Antik toplumlarda kadının statüsü için bknz: Esra Yalazı, \& Sultan Deniz Küçüker. "Ksenophon'un Oikonomikos adlı eserinde evlilik ve kadına yaklaşım." Archivum Anatolicum-Anadolu Arşivleri 9.2 (2015): 57-90.

45 Hydatius, Procopius, De belloGothico, H. B. Dewing (ed. and tr.), LCL (Cambridge, MA, 1914). 1.3.23

46 Herwig Wolfram,The Roman Empire and its Germanic Peoples, 167

47 Hyd., Chron. 301.4.

48 Hyd., Chron. 301.4. 
III. Valentianus'un genç olmasından dolayı güç dengeleri annesi Galla Placidia; Batı İmparatorluğunun Magister Militum'u Constantius Felix, kıdemsiz Magister Militum Flavius Aetius ve Afrika Comes'i Boniface aralarındaki mücadele sonucu sürekli taraf değiștiriyordu ${ }^{49}$. Bu kaotik ortamdan kurtulmak isteyen Boniface özellikle Constantinus Felix ve Flavius Aetius'un kazandığı başarılara karşılık kendi hamlesini yapmak istemiştir. Bunun için de Vandallar güzel bir hedef olarak durmaktadır. Çünkü Gotların Süevlerin konumunu güçlendirmesiyle İber Yarımadası'nda sıkışan Vandallar'ın hizmetini almak Boniface için mantıklı bir hamle olarak durmaktadır. Geiserich için ise durum farklıdır. Gotların ve Süevlerin kendi konumlarını güçlendirmesiyle iyice sıkışan Geiserich'de gözünü Roma'nın Afrika'sına dikmek zorunda kalmıştır. Bu Vandalların Afrika'ya geçişindeki birinci motivasyonudur. İkinci motivasyon ise Batı Afrika'nın Romalılar kadar güçlü birliklerle korunmamasından ileri gelmektedir ${ }^{50}$. Roma özellikle 410 yılında yaşadığı felaketten sonra güçlerinin önemli bir kısmını başta İtalya ve Gallia'nın savunmasına ayırmıştır. Geiserich bu konjonktürü son derece iyi gözlemlemiştir. 3. Motivasyon kaynağı ise 410 yılında Roma'yı yağmalayan Alaricus'un de nihai amacının Afrika'ya ulaşmak olmasıdır. Çünkü bu barbar olarak adlandırılan topluluklar bu bölgede diğer kavimlerle mücadele etmek gibi önemli bir yükten kurtulacaklarını aynı zamanda zengin Afrika'nın kabilelerini önemli ölçüde doyurabileceğini düşünmekteydiler. Bu vizyon Alaricus'da vardı; aynı öngörüye Geiserich'de sahipti.

Vandalların geçiş aşaması ile ilgili en net bilgileri Hydatius verir. Hydatius Vandalların Mayıs ayında aileleriyle birlikte Hispania'yı terk edip Mauretinia'nın Baetica bölgesine geçtiklerini dile getirmektedir. Gerçekten de Afrika'nın Hispania'ya en yakın bölgesi bu tarif edilen bölge olarak görülmektedir. $\mathrm{Bu}$ yüzden Hydatius'un bu bilgisinin doğru olduğu bilim insanları tarafından düşünülmektedir. Sonuç olarak Mayıs 429 tarihi Vandalların Afrika'ya geçtiği tarih olarak kabul edilmektedir. Victor Vitensis ise yaklaşık 1000'er kişilik gruplar halinde 80 tane geminin kullanıldı̆̆ını dile getirmektedir. Victor Vitensis Geiserich'in oğlu olan Huneric dönemine şahit olmuştur; haliyle bu verdiği bilgilerin herhangi bir doğruluk payı yoktur. Kendisinden sonra yine bu konuya eğilen bir başka müellif Procopius ise 80000 sayını gerçekçi bulmamaktadır ${ }^{51}$. Bunun Geiserich'in bir propaganda yönetimi olduğunu dile getirmiş ve gerçek sayının ancak 50000'ler civarında

49 Ian Hughes, Gaiseric: The Vandal who Destroyed Rome. Pen and Sword, 2017.,108

50 Andrew Merrills \& Richard Miles. The Vandals, 51.

51 Procopius, $B V$ III.5.18-20. 
olabileceğini söylemiştir ${ }^{52}$. Ayrıca o dönemin gemi yapılarına bakılacak olursa 1000 kişinin sığabileceği büyüklükte 80 geminin olması son derece gerçek dışıdır; haliyle bu bize nakil olayının uzun sürdüğünü, Haziran ya da Temmuz ayına kadar sürdüğünü düşündürmektedir. Gerçekten de Haziran veya Temmuz önermesi mantıklı gözükmektedir. Bunun temel sebebi ise bunca insanın lojistiğinin nasıl sağlanacağı ve bu sağlansa dahi bu kadar uzun süreli bir nakil işleminin uzaması gerektiği anlamını taşımaktadır. Bu süreçte elbette Roma donanmasinın bu duruma herhangi bir müdahalede bulunamadığını da dile getirmek durumundayız çünkü Roma donanmasının büyük bir bölümü Hispania'da Vandallar tarafından ele geçirilmiştir; dolayısıyla Roma İmparatorluğu'nun yeni bir donanma toplayıp saldırıya geçmesi olanaksızdı.

Bir başka dikkat çekilmesi gereken başka bir husus ise geçişin nasıl bu kadar sağlıklı gerçekleştirildiğidir. Bu da açık bir şekilde bize Vandalların geçiş yaptıkları bölgenin korunaklı bir şehir olması gerektirdiğini düşündürmektedir. Burada aranması gereken iki kriter mevcuttur. Bunlardan ilki Afrika'ya geçişe elverişli ve Afrika kıyısına yakın bir şehir olması; ikincisi ise şehrin korunaklı olması gerekliliğidir. Çünkü bu geçişin en azından 3 aylık bir süre zarfında tamamlandığı göz önüne alınacak olursa Vandalların Hispania'da kalan kısmının saldırılara açık bir konumda olduğunu düşünmek gerekmekteyiz. Bu açıdan bakılacak olursa Hispania'nın Afrika'ya geçişin en yakın olduğu şehirler Carteia ve Mellaria'dır. Bu iki şehirde neredeyse Afrika'ya geçmek için mükemmel noktalarda yer almaktadır. İkisi de korunaklı şehir duvarlarına sahiptir. Dolayısıyla bu iki şehirde geçişi sağlıklı bir şekilde gerçekleştirebilmek için mükemmel gözükmektedir. Ancak Hydatius başta olmak üzere herhangi bir müellif hangi şehirden geçildiğini belirtmemiştir. Ancak Hydatius'un Carteia ile herhangi bir istila bilgisi vermemesi ve Roma'nın kurduğu geniş yol sisteminin Sevilla'dan doğrudan Mellaria'ya (modern Tarifa'nın yakınında yer almaktadır) gelmesi geçişte bu şehrin kullanıldığını düşündürmektedir ${ }^{53}$. O halde Mellaria'nın önemi hem Hispania'dan Afrika'ya geçişte en kısa mesafede bulunması hem de duvarının olmasıdır. Ancak bu kentin başka bir önemi ise küçük bir limana sahip olmasıdır. Bu özelliklere bakacak olursak Vandalların bu noktayı tercih etmeleri son derece olası gözükmektedir. Ancak bu noktada yine problem ortaya çıkmaktadır. Vandalların Afrika'ya nerede çıkmıştır sorusu. Bu sorunun yine kesin bir cevabı bulunmamaktadır. Bunun nedeni dönemin veya

52 Zosimus VI.3.2; Orosius, Hist. VII.40.9; Vict. Vit., HP I. 2 Seeesp. Goffart (1980), s. 2314, Gil Egea (1998), 189-92.

53 Andrew Cain,. "Miracles, Martyrs, and Arians: Gregory of Tours Sources for his Account of the Vandal Kingdom." Vigiliae Christianae (2005): 412-437. 
çağdaşlarının bu konu hakkında herhangi bir bilgi vermemesinden ileri gelmektedir. Yine bu açıdan problem okunmaya çalışılırsa Afrika'da Vandalların muhtemelen ele geçirmek isteyecekleri iki önemli kent vardır bunlar Tangiers ve Ceuta'dir ${ }^{54}$. Ancak yine bu şehirlerde Roma garnizonlarının olduğu düşünülecek olunursa şartlar bizi bir başka kente götürmektedir. $\mathrm{Bu}$ kent ise Exilissa kentidir. Bu kent Tangiers ve Ceuta kentinin tam kesişiminde yer almaktadır ${ }^{55}$. Bu kesişim noktasının olmasının yanında şehrin limanı doğrudan korunaklı bir çevre yapısına sahiptir. Aynı zamanda şehri karadan ulaşım ise son derece zahmetli ve zordur. İşte bu nedenler bu noktanın seçildiğini modern tarihçilere düşündürtmektedir.

\section{Vandalların Afrika'daki İlk Üssü:}

Vandalların Afrika'ya geçişi elbette Roma İmparatorluğu üzerinde büyük bir şok dalgası yarattı. Ancak burada sorgulanması gereken neden yerel Tingitana Comes'inin Vandallara müdahale etmediğidir. Tingitana Comes'inin yaklaşık olarak 6 ila 7000 civarında birliğe komuta ettiği düşünülmektedir $^{56}$. Bu sebepten ötürü yaklaşık olarak 80000 kişilik bir topluluğun en azından 20000 savaşçısı olduğu düşünülmektedir. Dolayısıyla Tingitana Comes'i Vandalların geçişine müdahale etmemiş Afrika içerisinde rahat hareket etmesine imkân sağlamıştır. Ancak elbette Vandalların 80000 kişi ile Afrika'ya çıktığ 1 Roma ve Ravenna'ya bildirilmiştir ${ }^{57}$. Burada iki temel unsur vardır. Bunlardan ilki Afrika'nın Roma için son derece önemli olması ikincisi Roma'ya giden ticaret güzergâhlarının ve tahıl yolunun tam ortasında yer alması. Bu iki özel durum Afrika'yı Roma için kaybedilmez kılmıştır. Bu nedenle Bonifatius hızlı hareket etmek istedi. Ayrıca Afrika'dan gelen haberler son derece kötüydü. Cartena, Caesarea, Saldae ve Sitifis Vandallar tarafindan yağmalanmıştı. Vandalların bu yürüyüşü çok uzun zaman alıyordu. Çünkü 20000 kişilik ordunun haricinde yaklaşık olarak 60000 kişilik kadınlar, çocuklar ve yaşlılardan oluşan seferi bir topluluk vardı. $\mathrm{Bu}$ bile esasında Bonifatius'a büyük bir avantaj sağliyordu. Bonifatius yaklaşık olarak 30000-35000 arasında askerle Geiserich ile yüzleşti. Savaş kaçınılmazdı. Bonifatius'un ordusunun yerel akınları durdurmak ve küçük sınır çatışmaları yaşamaktan başka bir savaş tecrübesi yoktu. 20000 kişilik Vandal ordusu Ren'den itibaren Afrika'ya geçiş sürecine kadar sürekli savaş

\footnotetext{
54 Ledward, Kenneth. "Spainand the Tangier Question." Fortnightly123.737 (1928): 699-707.

55 Ian Hughes,. Gaiseric: The Vandal who Destroyed Rome. Pen and Sword, 2017, 132.

56 Hughes, Ian. Gaiseric:,133; Margaret Roxan,. "The Auxilia of Mauretania Tingitana." Latomus 32. Fasc. 4 (1973): 838-855.

57 Andy Merrills \& Richard Miles, The Vandals, 53-54.
} 
halindeydi. Dolayısıyla savaş tecrübeleri son derece yüksekti ${ }^{58}$. Her ne kadar sayı üstünlüğü Bonifatius'ta gözükse dahi tecrübe açısından Vandal ordusu daha avantajlıydı. Savaş sonucunda Romalılar yenildi. Bonifatius Hippo Regius kentine sığınmak durumunda kaldı ${ }^{59}$.

Haziran 430 yılında ise Vandalların gerçekleştirdiği Afrika içerisindeki yürüyüş nerdeyse 1. yılına gelmişti. Bu ayda Vandallar tarihte ve Hristiyan dünyasında çok önemli bir şahsiyet olarak görülen Aziz Augustinus'un şehri Hippo Regius önlerine gelmiş şehri kuşatmaya almışlardı. Şehir kuşatmaya son derece hazırlıksız olarak yakalanmış ve gerekli yiyecek ve su takviyesi yapılmamıştı ${ }^{60}$. Ancak şehir her şeyden öte Aziz Augustinus'in şehri olarak biliniyordu ve sembolik anlamı Romalılar açısından son derece büyüktü. Bu koşullar altında şehir yıkıcı bir kuşatmaya girdi. Ancak şehrin kuşatılmasının ardından 3 ay geçtikten sonra Aziz Augustinus 28 Ağustos 430 tarihinde hayatını kaybetti. Bundan sonra şehir yaklaşık olarak 11 aylık süre zarfında direnmeye devam edecekti ${ }^{61}$. Bu süreçte Doğu İmparatorluğu Vandalları Afrika'dan atmak için başlarında ünlü generalleri olan Aspar ile birlikte büyük bir orduyu Afrika'ya gönderdi. Bonifatius' da bu orduya katıldı. Kuşatmanın yaklaşık olarak 14. ayında Hippo Regius kentinin hemen dışında yine bir savaş yaşandı. Sonuç Vandallar açısından tam bir galibiyetti. Gelecekteki Doğu Roma İmparatoru olan Marcianus bu savaşta Aspar'ın Domesticus'u konumundaydı. Marcianus Geiserich'e esir düştü ${ }^{62}$. Bonifatius şehri savunmanın artık beyhude olduğunu düşündüğünden firsattan istifade şehir halkı ile birlikte şehri terk etti. Şehirde başta yiyecek olmak üzere hayatta kalmak için pek çok gerekli olan temel ihtiyaçlar karşılanamaz düzeydi. Bu sebepten dolayı şehir halkı Vandalların kuşatmasını firsat bilerek şehri terk ettiler. Vandallar 14 ayın sonunda şehre nihayet girmişlerdi.

Hippo Regius kenti pek çok açıdan bakıldığında gelecekte yapılacak olan saldırılar için bir üs olarak kullanılacaktı. Böylelikle Geiserich Afrika’ya adım attığı tarihten yaklaşık olarak 18 ay sonra ilk başkentini bu kentte kurmuştu ${ }^{63}$.

\footnotetext{
58 Ian Hughes, Gaiseric, 133; Andy Merrills \& Richard Miles, The Vandals, 55.

59 Andy Merrills \& Richard Miles, The Vandals, 54.

60 Edward Charles Howard, "A note on the Vandal occupation of Hippo Regius." The Journal of Roman Studies 14.1-2 (1924): 257-258.; Dennis, Holmes VM. "Another note on the Vandal occupation of Hippo Regius." The Journal of Roman Studies 15.2 (1925): 263-268.

61 Peter Brown, Augustine of Hippo: a biography. (Univ of California Press, 2013); 78.

62 Andy Merrills \& Richard Miles, The Vandals, 55.

63 Andy Merrills \& Richard Miles, The Vandals, 56.
} 
Ancak Hippo Regius'un Vandal kontrolündeki durumu biraz karışıktır. Bunun temel sebebi 432 yılında her ne kadar şehir Vandalların kontrolüne geçmiş olsa da esas olarak şehrin statüsü resmi olarak belirlenmemişti. Vandallar 432 yılından itibaren Roma Afrikası'nın önemli bir kesiminde ciddi anlamda yağma faaliyetlerinde bulunmuştu ${ }^{64}$. Bu yağma faaliyetlerinden dönemin kaynaklarından anlaşıldığı kadarıyla yalnızca 3 kent nasibini almamıştı. Bunlar aynı zamanda Roma Afrika'sının önemli kentlerinden olan Cirta, Hippo ve Kartaca idi. Bu arada Felix'in ölmesiyle birlikte Roma İmparatorluğu'nda da iç çalkantılar başlamıştı. Bonifatius her ne kadar Vandal problemiyle uğraşsa da Batı Roma İmparatorluğu'ndan destek istemişti. Aetius Vandallara karşı yapılacak bu sefere her ne kadar destek vermek istemişse de Frankların Gallia'yı istila girişimleri üzerine bunu gerçekleştirememiştir. Bu sıralarda tarihler 432 y1lını göstermektedir. Aetius Franklarla bir anlaşmaya varmış ve Frankların ele geçirdiği Roma şehirlerinde yeniden kontrol sağlamıştır. Ancak Afrika'dan gelen haberler İmparatorluk içerisinde büyük bir ümitsizlik yaratmış özellikle 2. Hippo Regius savaşından da yenilgi haberleri gelince Aetius ve Bonifatius arasındaki güç mücadelesi zirveye çıkmış; bunun üzerine Bonifatius Afrika'dan ordusuyla birlikte İtalya'ya yelken açmıştır. Bunun temel sebebi Galla Placidia tarafından çağrılmış olmasıdır. Muhtemelen Galla Palcidia Aetius aşırı derece güçlendiğini düşünüp kendisine doğrudan bir tehdit olarak algılamıştır. Batı ordularının en rütbeli komutanı olarak Bonificus magistermilitum et patricius unvanını kullanmaktadır. Bu Batı Roma İmparatoluğu'nda hem askeri hemde sivil idarenin en yetkili unvanı olarak görülmektedir. Bonifatius'un İtalya'ya yelken açması haberini alan Aetius hızlı bir şekilde hareket ederek ordusuyla birlikte Süevlere karşı bir sefer hazırlığındayken ani bir kararla Gallia'dan İtalya'ya dönmüştür ${ }^{65}$. İki orduda Rimini kentinin hemen dışında konuşlanmıştır. Savaşın sonucu Aetius için tam bir felakettir. Bu savaşın neticesinde Aetius kesin olarak yenilmiş ve İtalya'da yer alan malikânesine çekilmeye zorlanmış, bütün mevki ve makamlarından azledilmiştir. Ancak kısa bir süre içerisinde Bonifatius hayatını kaybetmiş ve onun makamlarını ele geçirmiştir ${ }^{66}$.

$\mathrm{Bu}$ sırada Geiserich ise Roma Afrika'sının neredeyse her yerinde yağma faaliyetlerini sürdürüp kendi konumunu güçlendirmektedir. Batı Roma İmparatorluğu üzerindeki Hun tehdidi ise Afrika'da yaşananlara müdahale imkânını ortadan kaldırmıştır. Bu sebepten dolayı 11 Şubat 435 yılında

64 Ian Hughes, Gaiseric:, 141-2.

65 Jeroen WP. Wijnendaele, Thelast of the Romans: Bonifatius-warlord and comes Africae. (Bloomsbury Publishing, 2015), 45

66 Andy Merrills \& Richard Miles, The Vandals, 54. 
Vandallar ve Batı Roma arasında bir barış anlaşması tesis edilmiştir. Bu anlaşma neticesinde Hippo Regius kentinin statüsü nihayet resmiyete kavuşmuş oluyordu. Ayrıca anlaşma neticesinde Vandallara Afrika'da geniş topraklar verilmiş ve bu Batı Roma İmparatorluğu tarafindan resmi olarak tanınmıştır. Numidia eyaletinin kıyı kesimleri ve Mauretania'nın bazı bölgeleri resmi olarak Vandallara verilmiştir. Hippo Regius ise 435 y1lında başkent statüsüne kavuşmuştur ${ }^{67}$.

\section{Sonuç:}

Vandallar'ın gerçekleştirdiği bu göç dalgası özüne bakılacak olursa bir hayatta kalma mücadelesinden daha öte bir şey değildir. Kavmin ilk yıllarıyla ilgili bilgi azlığı hem Roma görüş sahasına uzaklığından hem de kuvvetli bir kavim olmadığından ileri gelmektedir. Kavimle ilgili bilgiler V. yüzyılın hemen başlarında artmaktadır. Bu artışın temel nedeni Roma'nın görüş sahasına girmesinden ileri gelmektedir. $\mathrm{Bu}$ görüş sahasına girme; yalnızca sözde kalmamış bizzat Roma'nın sınırlarından içeri girmişlerdir. Tarihte yaptıklarıyla bir toplumun hatta bazen dünyanın ilgisini çekmiş liderler söz konusudur. İşte bunlardan birisi de Geiserich'dir. Geiserich yalnızca kendi toplumuna mal olmamış aynı zamanda da dünya tarihini yakından ve derinden ilgilendiren eylemlerde de bulunmuştur. Afrika'da kurulan Vandal Krallığı artık yalnızca hayatlarını kurtarmak için başka kavimlerin önünden kaçan bir topluluktan ziyade dünya tarihini değiştirecek bir devlet konumuna yükselmiştir. Bunun da baş müsebbibi Geiserich'tir.

\section{KAYNAKÇA}

Berndt, Guido M.,and Roland Steinacher. Das Reich der Vandalenundseine (Vor-) Geschichten. Vol. 13. Verlag der Österreichischen Akademie der Wissenschaften, 2008.

Brown, Peter. "Christianity and local culture in late Roman Africa." TheJournal of Roman Studies58.1-2 (1968): 85-95.

Brown, Peter. Augustine of Hippo: a biography. Univ of California Press, 2013.

Cain, Andrew. "Miracles, martyrs, andarians: Gregory of Tours' sourcesfor his account of the Vandal kingdom." Vigiliaechristianae (2005).

Dennis, Holmes VM. "Anothernote on the Vandal occupation of HippoRegius." TheJournal of Roman Studies15.2 (1925):263-268.

Dexippus, Fragments, Karl Müller (ed.), FHG III (Paris, 1849), Fr. VI.

67 Andy Merrills \& Richard Miles, The Vandals, 56. 
Garnsey, Peter. "Taxatio and pollicitatio in Roman Africa." The Journal of Roman Studies 61 (1971): 116-129.

Gasparini, Valentino. "Tracing Religious Change in Roman Africa." Eds. R. Raja-J. Rüpke, A Companion to the Archaeology of Religion in the Ancient World. Malden-Oxford(2015): 478-488.

Gibbon, Edward, History of theDeclineand Fall of the Roman Empire (London, 17761789), ed. David Wormesley, 3 vols. (London, 1994).

Heather, Peter. "Gaiseric, king of theVandalsandAlans, 428-477 CE." Oxford Research Encyclopedia of Classics. 2015.

Herwig Wolfram, "Norbert Wagner, Getica. Untersuchungen zum Leben des Jordanes und zur frühen Geschichte der Goten." Institut für Österreichische Geschichts forschung, Mitteilungen 76 (Wien, 1968): 256.

Heylyn, Peter, Cyprianus Anglicus: Or, The History of the Life and Death, of the Most Reverend and Renowned Prelate William by Divine Providence, Lord Archbishop of Canterbury... Containing also the Ecclesiastical History of the Three Kingdoms of England, Scotland, and Ireland from His First Rising Till His Death, A. Seile, 1719.

Howard, Edward Charles. "A note on the Vandal occupation of HippoRegius." The Journal of Roman Studies 14.1-2 (1924):263-268.

Hughes, Ian. Gaiseric: The Vandal Who Destroyed Rome. Pen and Sword, 2017.

Hydatius, Lemicus. The Chronicle of Hydatius and the Consularia Constantinopolitana: two contemporary accounts of the final years of the Roman Empire, Clarendon Press, Oxford, 1993.

Hydatius, Procopius, De bello Gothico, H. B. Dewing (ed. and tr.), LCL (Cambridge, MA, 1914).

Iordanes, and Alfred Holder. Iordanis De Origine Actibusque Getarum. Mohr, 1882; XXII, 115 .

Istvánovits, Eszter, and Valéria Kulcsár. "Sarmatians or Germans: Influence or Ethnic Presence Oldproblem-Newhypotheses." Inter Ambo Maria Northern Barbarians from Scandinavia towards the Black Sea(2013): 146.

Jerome, Epistulae, I. Hilberg (ed.), CSEL 54 (Vienna, 1910), 123.16.

Jones, Arnold HM. "Thedateandvalue of the Verona List." TheJournal of Roman Studies44.1-2 (1954): 21-29.

Ledward, Kenneth. "Spainand the Tangier Question." Fortnightly 123.737 (1928).

Mallan, Christopher, andCaillanDavenport. "DexippusandtheGothicInvasions: Interpreting the New Vienna Fragment (Codex Vindobonensis Hist. gr. 73, ff. 192 v-193 r)." The Journal of Roman Studies 105 (2015): 203-226.

Merrills, Andrew, Vandals, Romans and Berbers: New Perspectives on Late Antique North Africa, Routledge, 2017.

Merrills, Andy \& Richard Miles, The Vandals, Wiley Blackwell, 2010. 
Mierow, C. Charles, The Gothic History of Jordanes in English Version: With an Introduction and Commentary. Princeton University Press, 1915.

Millar, Fergus. "Local Cultures in the Roman Empire: Libyan, Punicand Latin in Roman Africa." The journal of roman studies 58.1-2 (1968): 126-134.;DuncanJones, Richard P. "City population in roman Africa." The Journal of Roman Studies 53.1-2 (1963): 85-90.

Opreanu, C. "Roman Dacia and its barbarian neighbours. Economic and diplomatic relations." Oxbow Monograph (1997): 247-252.

Pohl, Walter, "The Vandals: fragments of a narrative", Vandals, Romans and Berbers. Routledge, 2017.

Price, Simon. "Latin Christian Apologetics: Minucius Felix, Tertullian, and Cyprian." Apologetics in the Roman Empire: Pagans, Jews, and Christians (1999): 105130.

Quinn, Josephine Crawley, Roman Africa? Digressus Supplement, 1, 'Romanization'?, : The Institute of Classical Studies, (2003): 7-34

Randers-Pehrson, Justine Davis. Barbarians and Romans: the birth struggle of Europe, AD 400-700. Taylor \& Francis, 1983

Roxan, Margaret. "The auxilia of Mauretania Tingitana." Latomus 32.Fasc. 4 (1973):838-855.

Schenkl, Karl, Poetae Christiani MinoresI ...Probaecento, Tityrussiue Versus ad gratiam Domini, De uerbiin carnatione, De ecclesia, (Viena CSEL 16, 1, 1888):533-554.

Schmidt, Anna Magdalena. "Die Rhein überquerung der Vandalen, Alanenund Sueben-Ursachen, Datierung und Übergang." historia scribere 5 (2013):319335.

Shanzer, Danuta. 'Intentions and Audiences: History, Hagiography, Martyrdom and Confession in Victor of Vita's Historia Persecutionis', in A. H. Merrills (ed.), Vandals, Romans and Berbers: New Perspectives on Late Antique North Africa, 271-90, London, 2004.

Stirling Lea, M.,The koine of the cupula in Roman North Africa and the transition from cremation to inhumation. In D.L. Stone and L.M. Stirling (eds.), Mortuary landscapes of North Africa. (Toronto), 110-137.

Tausend, Klaus. "Bemerkungen zum Wandaleneinfall des Jahres 271" Historia: Zeitschriftfür Alte Geschichte (1999): 119-127.

Tertullianus, Quintus Septimius Florens. The Five Books of Quintus Sept. Flor. Tertullianus Against Marcion. Vol. 7. Clark, 1868.

Vössing, Konrad. Das Königreich der Vandalen. Verlag Phillipvon Zabern in Wissenschaftliche Buchgesellschaft, 2014.

Wagner, Norbert Getica: Untersuchungen zum Leben des Jordanes und zurfrühen Geschichte der Goten. Vol. 22. Walter de Gruyter GmbH \& Co KG, 2016. 
Wijnendaele, Jeroen WP. The last of the Romans: Bonifatius-warlord and comes Africae, New York, Bloomsbury Publishing, 2015.

Willis, James. Martianus Capella. Walter de Gruyter, 2012.

Wolfram, Herwig. The Roman Empire and its Germanic Peoples, Berkeley, 1997.

Wood, Ian. "Kings, Kingdoms and Consent", in P. H. Sawyer and Ian Wood (eds.), Early Medieval Kingship,6-29,Leeds, 1977.

Yalazı, Esra \& Küçüker, Sultan Deniz; "Ksenophon'un Oikonomikos adlı eserinde evlilik ve kadına yaklaşım." Archivum Anatolicum-Anadolu Arşivleri 9.2 (2015): 57-90.

Zosimus, Historicus Zosimus. Zosimi comiti sexadvocatifisci Historia Nova. Georg Olms Verlag, 2, 16, 3; Zosimus, Historicus, and Ronald T. Ridley. New history. Australian Assoc. for Byzantine Studies, 1982; 1963. 